\title{
Economic Uncertainty and Fertility
}

\author{
Michaela Kreyenfeld \\ (Max-Planck Institute for Demographic Research \& Hertie School of Governance)
}

\begin{abstract}
Sociologists and demographers have long been interested in the role of economic uncertainty in family behavior. Despite the prevailing "bourgeois conviction" that economic uncertainty discourages people from having children, the empirical evidence on this issue is mixed. In this paper, I summarize the recent empirical evidence, and discuss the potential limitations of previous investigations. Among the possible shortcomings of these studies is that many relied exclusively on unemployment as an operational definition of labor market uncertainty. Subjective indicators of economic uncertainty, which measure the individual's perception of his or her economic situation more directly, often were not available to researchers. Moreover, few of these studies explored group-specific differences in behavior. In this paper, we seek to overcome some of the limitations of these earlier analyses. Based on data from the German Socio-Economic Panel (GSOEP), we study the role of perceived economic uncertainty in transitions to first and higher order births for the period 1990-2013. In addition, we examine how different population subgroups (stratified by education, parity, and age) respond to economic uncertainty.
\end{abstract}

Keywords: Fertility, family, unemployment, economic uncertainty 


\section{Ökonomische Unsicherheit und Fertilität}

\section{Zusammenfassung}

Der Zusammenhang von ökonomischer Unsicherheit und Geburtenentwicklung ist ein Themenfeld, das gleichermaßen von soziologischer wie auch von demographischer Bedeutung ist. Obwohl theoretische Überlegungen zumeist der „,bürgerlichen Überzeugung“ verhaftet geblieben sind, dass ökonomische Unsicherheiten sich negativ auf das Geburtenverhalten niederschlagen sollten, haben empirische Studien in diesem Bereich eher uneinheitliche Befunde geliefert. Dieser Beitrag fasst aktuelle Studien zusammen und setzt sich kritisch mit den vorliegenden empirischen Befunden auseinander. Zum einen haben bisherige Studien zumeist nur Arbeitslosigkeit als Merkmal ökonomischer Sicherheit herangezogen. Subjektive Indikatoren, die unmittelbarer die aktuelle ökonomische Situation wiederspiegeln, waren in den bisher verwendeten Daten oft nicht verfügbar. Darüber hinaus haben nur wenige Studien sich der Frage gewidmet, ob unterschiedliche Subpopulation unterschiedlich auf ökonomische Unsicherheit reagieren. Mit diesem Beitrag soll ein Teil dieser Forschungslücke geschlossen werden, indem auf Basis der Daten des Sozio-Oekonomischen Panels (SOEP) der Jahre 19902013 der Einfluss der wahrgenommenen ökonomischen Unsicherheit auf die Geburtenentwicklung untersucht wird. Darüber hinaus wird die Frage in den Mittelpunkt gerückt, ob gruppenspezifische Unterschiede im Verhalten existieren und verschiedene Bevölkerungsgruppen (differenziert nach Bildung, Parität und Alter) anders auf ökonomische Unsicherheiten reagieren.

Schlüsselbegriffe: Arbeitslosigkeit, Fertilität, Familie, Ökonomische Unsicherheit

\section{Introduction}

Since the onset of the global financial crisis, scholars and policy-makers in Europe have become increasingly interested in examining the effects of economic uncertainty on family life and fertility behavior (Luci and Thévenon 2009; Promberger 2014; Richardson 2010; Sobotka et al. 2011; Testa and Basten 2014). However, empirical evidence on how the economic crisis has affected demographic behavior is still very limited. Most of our empirical knowledge of the effects of economic uncertainty on birth dynamics dates from the pre-crisis era. In these studies, unemployment (Adsera 2011; Del Bono et al. 2014; Gutiérrez-Domènech 2008; Huttunen and Kellokumpu 2012; Kravdal 2002; Kreyenfeld and Andersson 2014; Kreyenfeld 2010; Matysiak and Vignoli 2008; Neels et al. 2013; Özcan et al. 2010; Pailhé and Solaz 2012; Schmitt 2012a), as well as term-limited working contracts (De La Rica and Iza 2005; Gebel and Giesecke 2009; Vignoli et al. 2012) have been explored as potential influences on fertility postponement and transitions to higher order births. However, these studies have so far failed to produce conclusive evidence of an association between economic uncertainty and fertility. There are a number of possible reasons for the inconsistencies in the empirical literature. They may stem 
from the fact that group-specific differences in behavior were not sufficiently accounted for in many of the earlier studies. It may also be the case that the association between economic uncertainty and fertility is a recent phenomenon. In earlier decades, other factors, particularly ideational changes, were cited as the dominant reasons for first birth postponement and declining transition rates to higher order births. In the $21^{\text {st }}$ century, however, economic uncertainty has become omnipresent, and may have emerged as a driving force of birth dynamics.

In this paper, we seek to contribute in several ways to the growing body of empirical literature on the association between economic uncertainty and fertility. First, we provide recent empirical evidence of the association between economic uncertainty and birth transitions which includes periods both before and after the economic crisis. Second, we go beyond previous studies by including subjective measures of economic uncertainty in our investigation. Third, we explore group-specific differences in behavior. The paper builds on our own work, in which we investigated the effects of uncertainty on the employment careers of women and first birth hazards (Kreyenfeld 2010). While this earlier work was restricted to first-order births and to female respondents, the current paper provides results for all birth parities, and also draws upon information about the male partner's characteristics. The data come from the German SocioEconomic Panel (GSOEP). The GSOEP is the longest running panel in Europe (Wagner et al. 2007). Among the positive features of this data set are that it has reasonably large sample sizes and provides complete birth histories. Moreover, it asks respondents the same set of questions every year, including questions about each individual's perceptions of his or her personal economic situation. For this analysis, we restrict the investigations to the period 1990-2013. We employ event history modeling, whereby the dependent variable is the birth intensity in a given month. The key independent variable is a measure of the respondent's perceptions of his or her personal economic situation. The paper is structured as follows: in Section 2 we provide a summary of the previous empirical studies which led us to become interested in group-specific differences in behavior, in Section 3 we present data and descriptive statistics on birth behavior in Germany, in Section 4 we discuss the results from the multivariate results, and in Section 5 we conclude.

\section{Theoretical considerations}

\subsection{A historical perspective}

There is a widespread belief among scholars engaged in family research that adverse economic conditions lead couples to postpone family formation, and discourage them from having a larger family (e.g., Rindfuss et al. 1988). In demographic research, Malthus is usually given credit for being the first to have developed a conceptual basis for this assumption. While Malthus was not convinced that human beings have the capacity to control their reproductive behavior, the moral conviction that people should control their fertility under harsh economic conditions infused his work (Mombert 1907, p. 86). For much of northwest European history, this belief was reflected in societal norms and legal regulations which governed reproductive behavior (Friedlander 1992, p. 28). Until the beginning of last century, couples wishing to marry had to 
seek permission from the authorities, and their application for a marriage license could be refused if they were unable to demonstrate that they had a secure economic situation. At that time, economic security meant that the male breadwinner had the means to support a family without having to rely on public assistance. In southern Germany in particular, these regulations represented barriers to marriage for many couples, and were in place until the late $19^{\text {th }}$ century (Matz 1980, p. 29-36). While these marriage restrictions (Ehebeschränkungen) were gradually abolished over time, the bourgeois conviction that couples needed a stable economic situation before forming a family persisted.

The belief that economic security was a prerequisite for family formation formed the basis of many theoretical concepts that followed. Unlike Malthus, however, later demographers had to grapple with the fact that, by the early $20^{\text {th }}$ century, growing wealth and prosperity were negatively related to marriage and birth rates (Brentano 1910; Mombert 1907). Although social class, wealth, and income were not well defined concepts at that time, these works nevertheless contain important insights into the factors which likely contributed to the relationship between economic conditions and birth behavior. Brentano (1910, p. 375) observed that "social requirements" increased in tandem with rising social standing, and that families found it difficult to meet these requirements if they had a large number of children. Mackenroth (1953) later coined the term "Aufstiegswille" to explain why birth rates declined in the process of modernization. In his view, modernization had eroded class barriers and opened up the opportunity for large shares of the population to climb up the social ladder. Resources which were previously invested in raising children were redirected into achieving social upward mobility. Brentano (1910: 376) also cited the "altered position of woman" (ibid.: 376) and the "movement of emancipation" (ibid: 386) as additional reasons for the plunge in the birth rates. Even at that time, the "large increase in the proportion of women earning their own livelihood" (ibid.: 379) was regarded as one of the reasons for the decline in birth and marriage rates.

The ideas outlined above have figured prominently in discussions of fertility ever since, and have been formalized in economic fertility models. Thus, it is generally assumed that birth rates have declined in large part because the opportunity costs of having children have increased as the wages and labor market opportunities of women have risen (Borg 1989; Schultz 1976; Willis 1987). While economists have narrowly focused on women's improved income opportunities, the second demographic transition theory (SDT)—which is, undoubtedly, the most important demographic concept regarding fertility dynamics developed during the second half of the 20th century-challenged the assumption that long-term fertility trends are attributable to economic factors. Based on sociological concepts of individualization and value change, the scholars who developed the SDT attributed the drop in fertility rates to a profound shift in ideas and attitudes, including women's emancipation and self-actualization (Lesthaeghe 2010; Van De Kaa 1987). Although the economic theories and the SDT approach were based on entirely different premises, they reached a very similar conclusion: namely, the fact that a growing share of women were working and achieving economic independence was the main reason why fertility had declined so dramatically in Europe.

The strand of literature that followed addressed the efforts of governments to accommodate the needs of working mothers. However, the assumption of many economic fertility models and of the SDT approach that work and family life were incompatible no longer seemed to be valid. 
Since the 1990s, variations in cohort fertility rates have been shown to be correlated with social policies designed to alleviate the incompatibility of work and family life. In particular, the high fertility rates of France and the Nordic countries were cited as evidence that integrating women into the labor market can help countries achieve replacement-level birth rates. Meanwhile, the low fertility observed in the German-speaking countries was attributed to the traditional family policies which were dominant in these countries (Caldwell and Schindlmayr 2003; EspingAndersen 1999; McDonald 2000; Neyer 2003). Micro-level studies grappled with the question of how the policy context can be integrated into fertility models in a convincing manner (Neyer and Andersson 2008). However, it became clear that the social policy context had become an essential variable which can be seen as mediating the relationship between economic and social conditions and birth behavior (Ellingsæter and Pedersen 2015; Kreyenfeld et al. 2012).

In addition to looking at social policy regulations, demographers have increasingly been investigating the question of whether economic uncertainty plays a significant role in variations in fertility rates across countries and within societies (Adsera 2011; Mills and Blossfeld 2003). This issue was initially raised in research on eastern Europe, where birth rates collapsed after the demise of the communist systems and the emergence of labor market uncertainty (Billingsley 2011; Sobotka et al. 2011). Since the global financial crisis hit all of Europe starting in 2007, economic uncertainty has often been cited in explanations of birth dynamics in contemporary societies.

\subsection{Economic uncertainty and fertility: Recent evidence}

Investigations based on aggregate-level fertility rates appear to support the idea that economic uncertainty is related to variation in national fertility rates (Goldstein et al. 2013; Lanzieri 2013; Sobotka et al. 2011). Many southern and eastern European countries, including crisis-ridden Greece, experienced declines in their birth rates in the aftermath of the downturn (Vlachadis et al. 2014). However, no clear relationship between changes in national unemployment rates and fertility has been observed in the rest of Europe. Most puzzling are the trends in the Nordic countries, which have seen radical declines in their period fertility rates since 2010. In Denmark, for example, the total fertility rate dropped from 1.9 in 2010 to 1.7 in 2013; and for no apparent reason (Statistics Denmark 2014). This decline was no less radical than the decrease in fertility rates seen in Greece after its economy collapsed. In light of these developments, it is difficult to evaluate the magnitude of the decline in birth rates in southern Europe, especially as period fertility rates are complex summary measures which can be distorted by tempo effects. Moreover, like all macro-level correlations, these investigations are subject to ecological fallacies.

Unfortunately, micro-level evidence on the association between economic uncertainty and fertility in the $21^{\text {st }}$ century is still sparse. There is evidence from the 2011 Eurobarometer survey which suggests that a household's financial situation is not related to the fertility intentions of its members. However, an individual's degree of certainty about whether his or her fertility intentions will be realized seems to be connected to changes in the financial situation of his or her household during the crisis (Testa and Basten 2014). Despite these findings, micro-level 
data on the effects of labor market uncertainty on real birth behavior, and on how this association has developed in recent years, remain limited.

Most of our knowledge about the effects of economic uncertainty on fertility dynamics dates from the time before the onset of the financial crisis. These studies used current unemployment (Özcan et al. 2010; Pailhé and Solaz 2012; Schmitt 2012a) and fixed-term working contracts (De La Rica and Iza 2005; Gebel und Giesecke 2009; Vignoli et al. 2012) as operational definitions of economic uncertainty. The type of occupation and the sector of employment were also used to capture employment security, based on the assumption that employment in particular occupations or in the public sector provides a greater degree of labor market security than self-employment or employment in private enterprises (Maul 2012). Most studies have found that male unemployment is associated with lower first birth transition rates (Neels et al 2013; Pailhé and Solaz 2012; Schmitt 2012a). However, the effect of female unemployment on first birth rates was shown to be weak in some studies (Kravdal 2002), and non-existent in others (Gutiérrez-Domènech 2008; Özcan et al. 2010; Vignoli et al. 2012). For Germany, the empirical evidence suggests that employed women have even lower birth rates than women who are unemployed or do not work for other reasons (Kreyenfeld 2010; Özcan et al. 2010; Schmitt 2012b; Schröder 2010).

Some of the inconsistencies in these findings may be attributable to the fact that the sample sizes used in many of these studies were too small to produce robust and significant results. After all, unemployment episodes are rare events in the life courses of women and men. Since the event of interest-i.e., birth—is also rare, researchers examining the unemployed population have often had to deal with very small numbers of events. The small sample sizes also did not allow researchers to conduct more subtle investigations which might have explored group-specific differences. In addition, scholars have expressed concerns that the unemployed population differ from the employed population in many respects (Del Bono et al. 2014; Huttunen and Kellokumpu 2015). Thus, the issue of unobserved population heterogeneity was not resolved in these studies (see also Schröder 2010 for a detailed discussion). Finally, current unemployment may not be a suitable measure for capturing economic uncertainty, as it merely reflects an individual's current labor market situation, and not his or her actual labor market options and career prospects. Subjective measures of economic uncertainty may therefore be a better indicator of the economic situation of an individual or a couple than the respondent's current activity status.

In this paper, we contribute to the empirical literature on the association between economic uncertainty and birth dynamics. We expand on our own prior analysis based on the German Socio-Economic Panel, in which we investigated the role of perceived economic uncertainty in first birth rates (Kreyenfeld 2010). The major finding of this study was that the association between the perception of economic uncertainty and the transition to a first birth was weak. However, the results also showed that there were differences based on educational level, as less educated women experienced elevated birth rates when they were subject to economic uncertainty. This earlier study was limited to the period 1984-2006, and thus to the pre-crisis era. It also covered a period prior to the launch by the German government of a major family policy reform designed to support maternal employment. Furthermore, it only looked at uncertainty in the employment careers of women, and at first birth rates. In the current study, 
we expand on this earlier analysis by including higher order births, and by taking into account the male partner's perceptions of his personal economic situation.

\section{Data and methods}

The data for this investigation come from the German Socio-Economic Panel Study (GSOEP). The GSOEP is one of the largest and longest running panel studies conducted in Europe (Wagner et al. 2007). Since the study was first launched in 1984, the respondents have been surveyed on an annual basis. In addition to having a reasonably large sample size, the GSOEP has a number of positive features, including the fact that it collects complete fertility histories. Each respondent's birth history is surveyed at the first interview, and is updated every year. Moreover, the GSOEP provides detailed employment histories, including information on each respondent's perceptions of his or her economic situation. Because it is a household panel, this information is available for all of the adult individuals who live in a given household unit. We can therefore include in our analysis the male partner's perceptions of his economic situation, and explore the interaction effects between the male and the female partners' attitudes.

The total sample of the 2013 GSOEP consisted of 87,095 respondents (including children). However, our study population is much smaller. First, we excluded from our study population respondents from the high income sample (sample $G$ ) as well as the recent immigrant sample (sample M). We furthermore restricted our analysis to female respondents who were between the ages of 17 and 47. We also limited the analysis to the years 1990-2013, and thus to the period of united Germany. We also restricted the sample to respondents who had participated in at least two consecutive survey years during that time. Cases with invalid information on key variables (such as year of birth, year of birth of children, migration background, or gender) were also omitted. If respondents dropped out of the sample, they were censored. However, respondents were allowed to reenter the study population. Thus, the data set has some minor gaps. Our final sample consists of 7,232 women at risk of having first birth, 4,407 women at risk of having a second birth, and 7,561 women at risk of having a third birth. The total number of first births was 1,842, the total number of second births was 1,507, and the total number of third births was 533 (for the occurrence and exposure tables, see Table A1 in the appendix).

The key independent variable of interest is the respondent's perception of his or her personal economic situation. ${ }^{1}$ This is a categorical variable which distinguishes between respondents who reported that they were not worried, that they were a bit worried, or that they were very worried about their personal economic situation. Employment status is captured by a variable which distinguishes between respondents who were participating in education, were unemployed, were in part-time employment, were in full-time employment, and were not in the job as a measure of subjective economic uncertainty (Kreyenfeld 2010). Since this paper already includes an array of models, I decided to restrict the analysis to personal economic worries. An advantage of this variable is that it applies to all respondents, whereas the fear of losing one's job is only relevant for the employed population. 
labor force (i.e., were not participating in the labor market but were not unemployed). It should be noted that the respondents' employment status was based on self-assessment. We cannot rule out the possibility that individuals who, based on official definitions, might have been classified as being out of the labor force because they were not seeking employment classified themselves as unemployed. In addition, the classification of being in part- or full-time employment was based on the self-assessment of the respondent, and does not necessarily follow the international guidelines on the definition of full-time employment; i.e., working 30 or more hours per week. Educational attainment is captured by a categorical variable which distinguishes between respondents who had not earned a university degree or a vocational training certificate (low), had received a vocational training certificate (middle), and had earned a college or a university degree (high). For the first birth analyses, age is the baseline intensity; while for higher order births, it is the duration since last birth. Age at first birth (categorized) is a control variable in the second and the third birth models. Another covariate is region, in which we distinguish between respondents who were living in eastern Germany and western Germany. We further distinguish between natives and migrants. Here we define a migrant as being a person who is a foreign citizen, or who was born outside of Germany. This is a rather wide definition of migrant status, but it is compatible with the definition commonly applied by the German Federal Statistical Office. We also control for partnership status, distinguishing between respondents who reported living with a partner, and those who did not have a co-residential partner. For coresidential episodes, we also make use of information on the (male) partner's perception of his economic situation. ${ }^{2}$

The data set is organized as a person-year data set. Many studies have used this panel information and employed discrete time hazard models for fertility research. In these models, the covariates in a given year were used to predict the probability of having a child in the subsequent year. Although this strategy is very straightforward, we did not follow it in this paper. Our main reason for using a different procedure is that the interviews in the GSOEP are conducted throughout the year. They peak in the beginning of the year, but several interviews are nevertheless conducted toward the end of the year. This creates a problem for any analysis which tries to use information in year $t$ to predict the birth probability in year $t+1$, as it cannot be ruled out that the respondent was already pregnant when the interview was conducted.

To ensure that we were measuring all of the covariates before pregnancy, we proceeded as follows. In a first step, we compiled the panel information in a person-year data set. Included in this data set was information on the exact month that an interview was conducted. We then generated an event history data set with monthly spell data. Obviously, we were only able to measure the characteristics of a respondent once per survey year; thus, this information is only available at different single points in time. To create an event history data set with monthly spells, we needed to make assumptions about how the characteristics measured at one point in time evolved between the panel waves. We therefore let the characteristics measured in a given 
year be constant until the next interview date. ${ }^{3}$ The date of childbirth (and censoring) was then backdated by nine months. Although we are actually modeling pregnancy intensities, we employ the terms "birth hazard" and "birth rates" to improve the flow of the paper.

In the following, we first display descriptive statistics to give an overall impression of the birth dynamics in Germany for the period 1990-2013. In the multivariate analysis, we employ Cox models to investigate the determinants of the first and the second birth rates. We run separate models for younger (aged 17-26) and older (aged 27-47) respondents to explore age-specific differences in the effects of economic uncertainty on first birth dynamics. We also investigate whether the influence of economic worries varied by level of education and calendar period by means of interaction models. These interaction models are, however, restricted to the first birth, because our small sample sizes prevented us from conducting similar kinds of interactions for higher order births. The final part of the multivariate information explores the effects of the partner's characteristics on first, second, and third birth dynamics. Here we examine whether the birth risks were reduced if the partner was very worried about his economic situation. We also study interaction effects between the economic concerns expressed by the female respondent and her partner, based on the assumption that couples will postpone birth decisions if both of the partners have economic worries.

\section{Descriptive results}

The GSOEP is a stratified survey, and several subsamples have been added over time. In particular, east Germans, migrants, and foreigners are oversampled in the data. In order to account for the oversampling of these different subpopulation in the descriptive statistics, we display survival curves and hazard rates by population subgroups. Here we distinguish between three groups: migrants, west Germans (without the migrant population), and east Germans (without the migrant population). The left panels of Figure 1 display the Kaplan-Meier survival functions for these three population subgroups. The hazard rates, which are displayed in the right panels of the figure, are calculated by dividing the number of events by the person-months of exposure for the interval given in the figure. To improve the readability of the figures, the hazard rates were multiplied by 1,000. Again, it is important to note that the date of childbirth was backdated by nine months. We refer here to childbearing risks, even though pregnancy intensities would be more precise.

The results shown in the figure are in line with previous findings on birth dynamics in Germany. The migrants were substantially younger than the non-migrants when they had their first child. We also find that the migrants were more likely than the non-migrants to have had a second or a third child. The figure further shows that the east Germans were younger than the west Germans at the first birth. However, the pattern was reversed for higher order births. While east Germans had higher probabilities of transitioning to a first birth, they had much lower probabilities than west Germans of progressing to a second- or a third-order birth. The survival

In some cases, the month of birth was missing. Here, we imputed this information. Sensitivity analyses in which we dropped the imputed cases from the analysis did not provide results which were much different from the results presented here. 
curves indicate that only 55 percent of the east Germans had given birth to a second child by the time their first child had reached age 10. Among the west Germans, the share was 66 percent. We also find pronounced east-west differences for third births. When the second child was 10 years old, 19 percent of the west Germans, but only 14 percent of the east Germans, had given birth to a third child. Among the migrant population, the share was 30 percent.

Figure 1: Transition patterns to the first, the second, and the third birth, 1990-2013

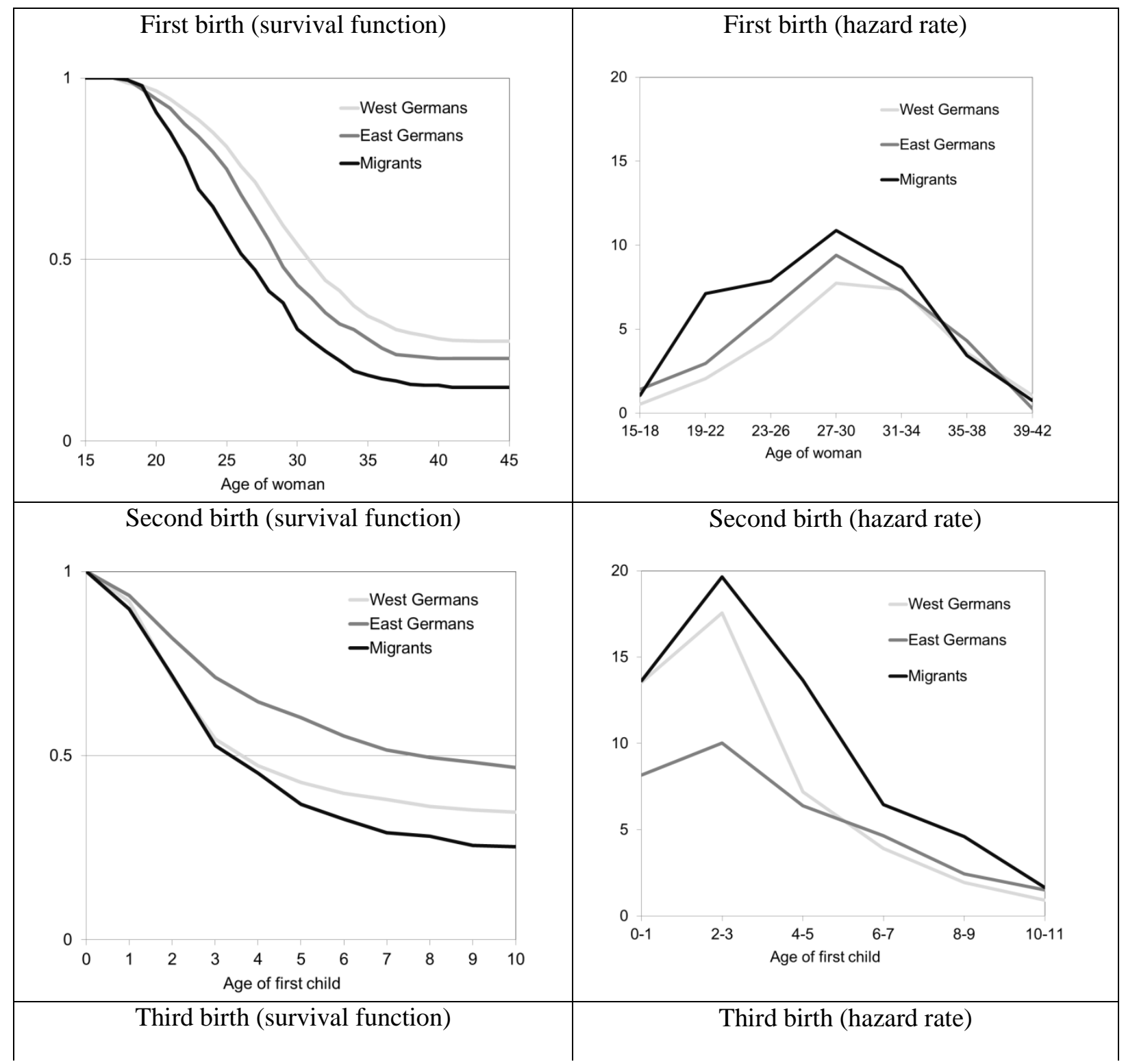



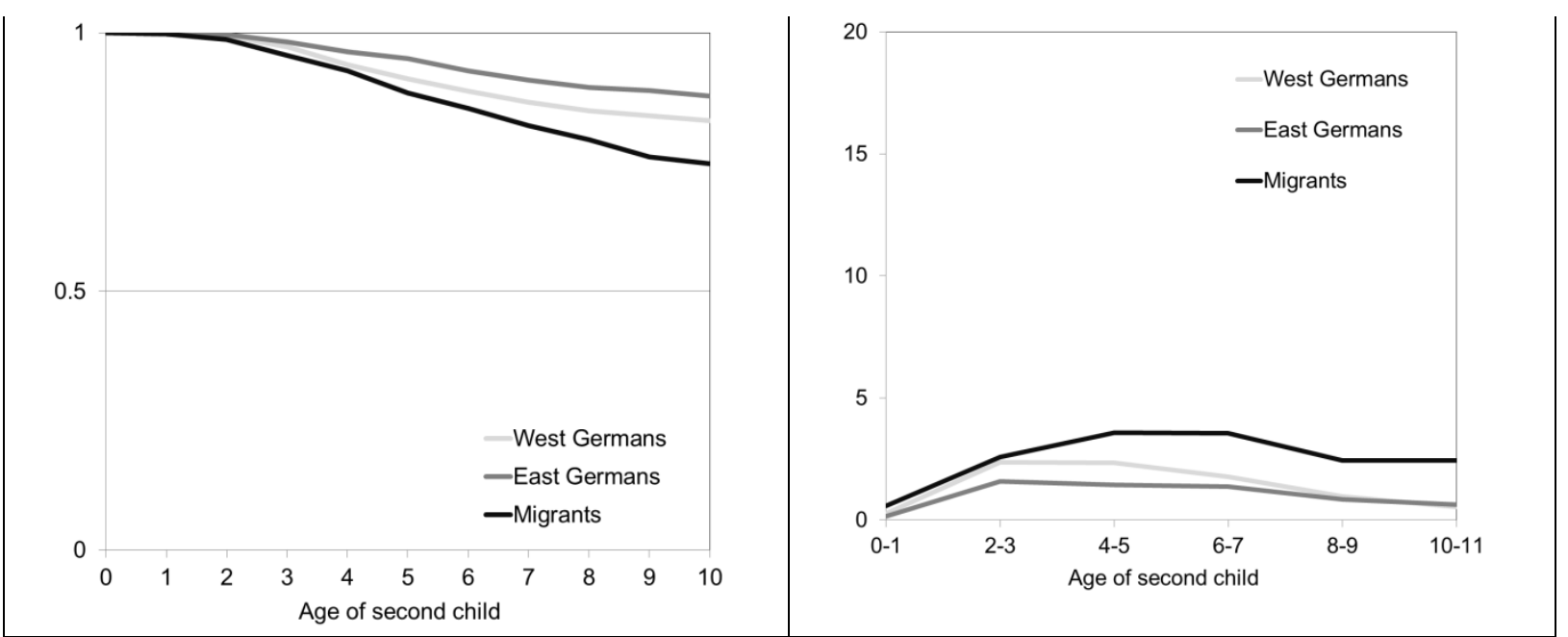

Note: The survival functions and the hazard rates were calculated from left-truncated data that include the period 1990-2013. The date of childbirth was backdated by nine month. The monthly hazard rates were multiplied by 1,000 and calculated by dividing the number of events and the time of exposure for the given categories. Source: GSOEP 1990-2013

\section{Multivariate results}

\subsection{First birth}

Table 1 reports the results from the first birth model. The first column displays the relative birth risks for the full sample; i.e., the sample which was not yet distinguished by age. We find that the birth risks declined over time, which is in line with our assumption that first parenthood is postponed in Germany over time. We also find that the east Germans had higher first birth rates than the west Germans, which is compatible with the descriptive findings discussed above. The migrants had higher birth rates than the non-migrants; a result which was also reported in the descriptive statistics. In addition, we find that having a high level of education accelerated the transition to the first birth. We assume this was because we control for educational participation and university graduates tend to start their family relatively soon after completing their education. Compared to those in full-time work, respondents who were participating in education have about 50 percent lower first birth risks. Not working or being in part-time employment was associated with lower first birth intensities (compared to those in full-time work). Unemployment was, however, unrelated to first birth progressions. We also controlled for having no partner in the household, which, unsurprisingly, lowered birth intensities substantially. The most important finding shown in this table is, however, that the perception of economic uncertainty does not appear to be related to fertility postponement.

We now turn to the question of whether different subpopulations respond differently to economic uncertainty. In the literature it has been posited that uncertainty early in the life course could be particularly detrimental for birth decisions (Mills and Blossfeld 2003). However, our empirical investigations suggest that the opposite is true (for similar evidence, see Kreyenfeld and Andersson 2014; Rendall et al. 2009). While economic uncertainty accelerates the transition to a first birth at younger ages (17-26), it reduces the transition to a first birth at older ages (27-47). How can we explain such a counterintuitive finding? According to the psychological literature, young women with limited labor market prospects may "rationally" opt for early motherhood as a means of structuring their otherwise uncertain life course 
(Friedman et al. 1994). Yet regardless of how we interpret our results for the younger age group, it is important to emphasize that most women in Germany do not seriously consider starting a family until after the age of 26. Among the respondents in this age group, economic concerns affected their birth decisions. Compared to women who said they were not worried about their economic situation, the birth intensities of the women who said they were worried were 22 percent lower.

Table 1: Results from the Cox model, relative risks of a first birth (baseline hazard: age of woman)

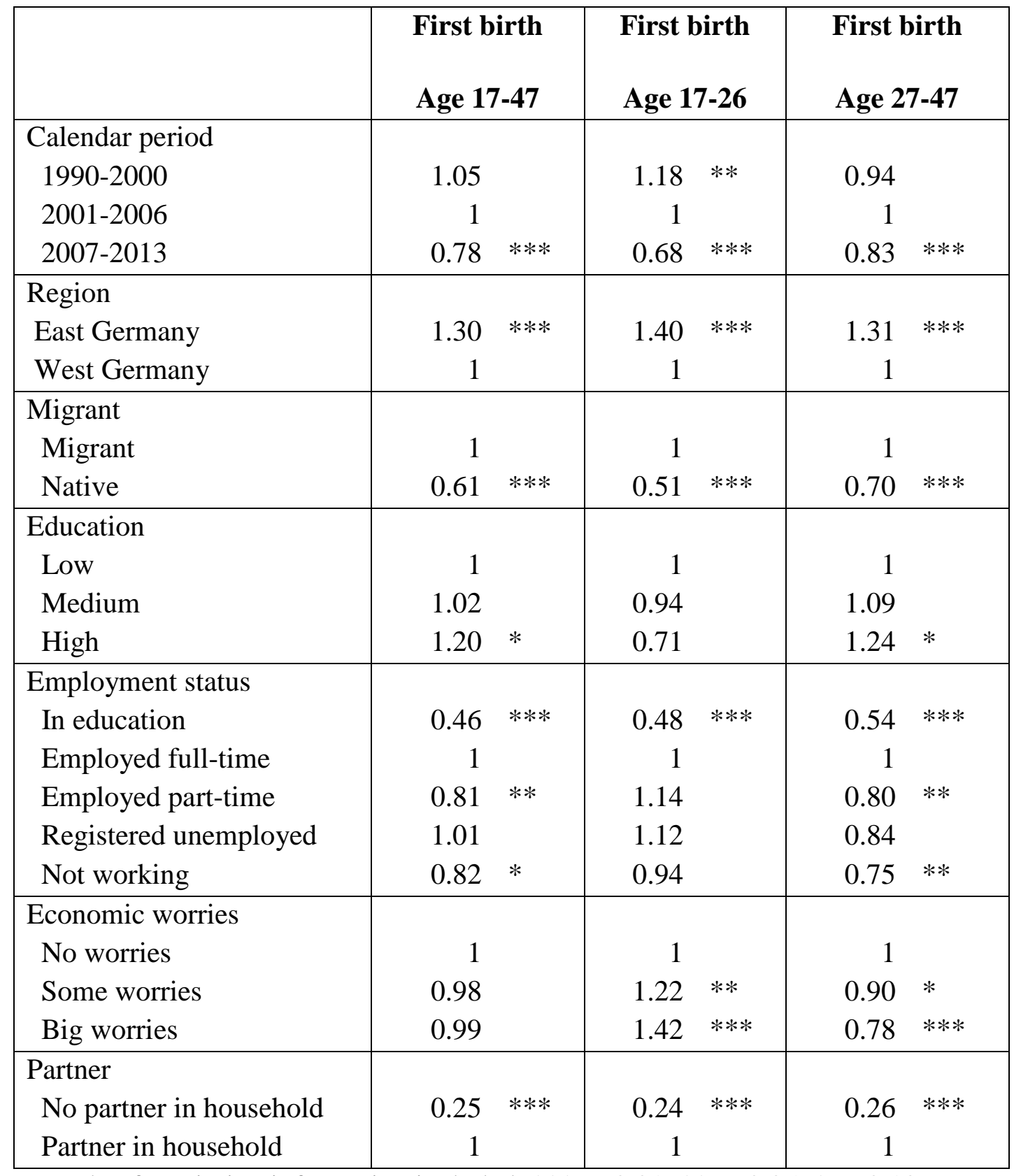

Note: Flag for missing information included; ${ }^{* * *} \mathrm{p}<0.01 ;{ }^{* *} \mathrm{p}<0.05 ;{ }^{*} \mathrm{p}<0.10$.

Source: GSOEP 1990-2013 
To further explore group-specific differences in behavior, Figure 2 reports results from an interaction model. Panel 1 of Figure 2 includes an interaction of the level of education and economic worries. The model shows that the gradient for the less and the highly educated women runs in opposite directions. While the less educated accelerated their transition to a first child when they were subject to economic uncertainty, the highly educated were less prone to have a child when they perceived that their economic situation was insecure. It should be noted that the gradient for the less educated is statistically significant; i.e., the respondents who were very worried behaved very differently from those who were not worried. Among the medium educated, the differences between those who were very worried and those who were not worried were also statistically significant. However, the interaction was not significant among the highly educated; this may be attributable to the small number of highly educated respondents in our data (see Table A1 in the appendix).

We also tested whether the effect of economic uncertainty and fertility had reversed over time (Panel 2 of Figure 2). This model specification was motivated by our assumption that the association between economic uncertainty and birth dynamics has become stronger over time. In particular in the case of Germany, the parental leave benefit reform which was enacted in 2007 created a new incentive structure for having children. Because the new parental leave benefit is tied to income, it incentivizes couples to postpone parenthood until both partners have an "acceptable" level of income. As can be seen in the right panel of Figure 2, we indeed find a positive gradient for the period after 2007. However, the interaction with calendar time is not statistically significant. 
Figure 2: Results from the Cox model, relative risks of a first birth

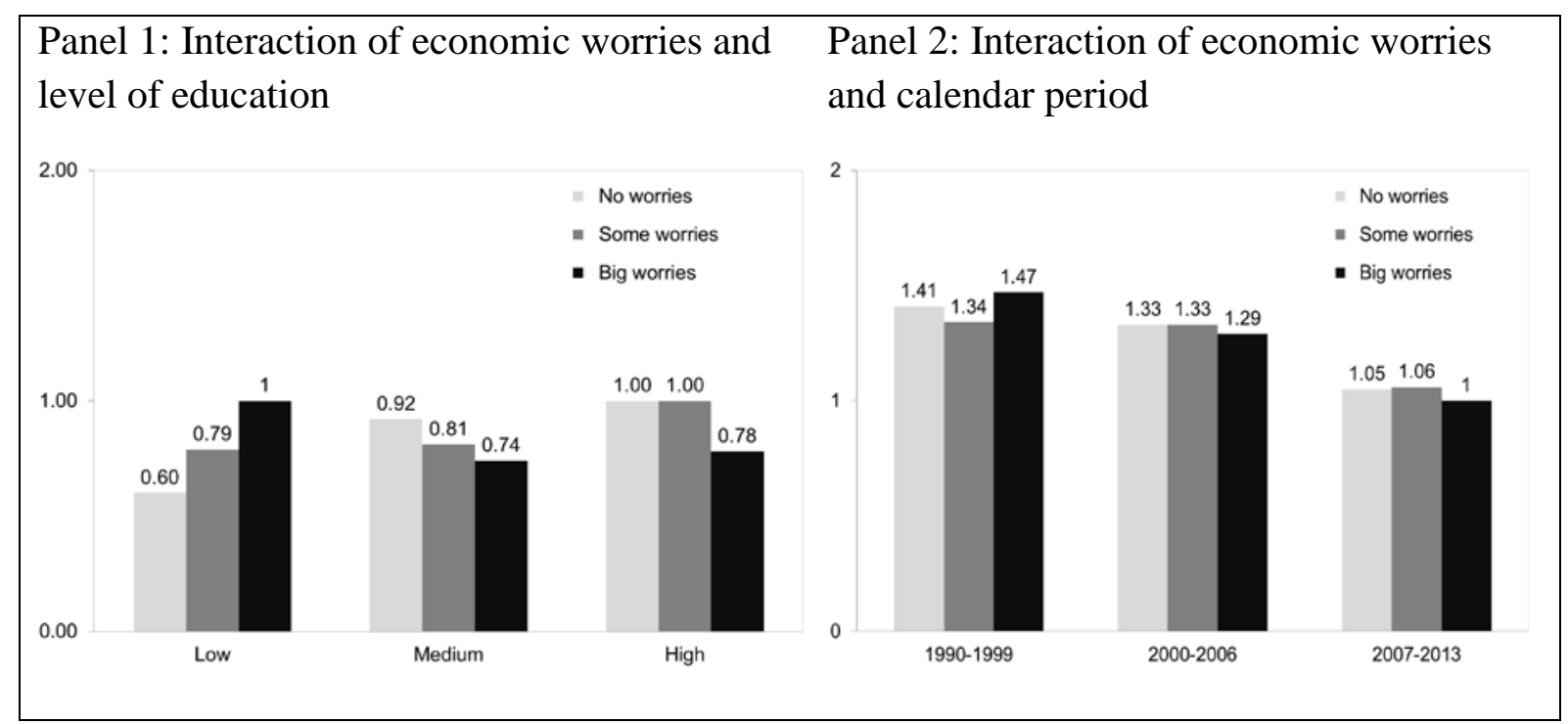

Further variables in model: Age (baseline), region, migrant status, employment status, flag for missing information, calendar period (Panel 1), and education (Panel 2).

Source: GSOEP 1990-2013

\subsection{Higher order births}

Table 2 reports the results for second and third births. We find very similar patterns for both of these birth orders. First, there were no major changes across time. It should be noted here that because the observation period is after 1990, we would not expect to see any major changes in higher order birth progressions — at least for west Germany, which dominates the overall pattern for the country. The east Germans had a lower risk of progressing to a second or a third child. This finding was already reported in the descriptive analysis. We also find that the migrants transitioned more rapidly to a second child. However, we do not observe any statistically significant differences between the migrants and the natives in the transition to a third birth. This finding is at odds with the descriptive statistics, which showed much higher third birth rates among the migrants than among the non-migrants. Apparently, some of the covariates in our models (in particular, employment status and education) explain some of the differences in higher order birth progressions between the natives and the migrants.

Having a university education was associated with higher second and third birth rates. This finding may be related to a "work-accelerated" pattern of childbearing among highly educated women. These women tend to space their births closer together, partly to minimize career interruptions, and partly because they start childbearing at later ages, and thus need to "squeeze" in their children into a shorter period of time before reaching the end of their reproductive period (Kreyenfeld 2002). The results for age at first childbirth are as we expected: the higher the age at first childbirth, the lower the second and third birth intensities. Living with a partner also 
shows the expected pattern of a strong increase in transition rates to a second and a third birth if there is a partner in the household. Women's full time-employment is shown to be associated with lower second and third birth rates. Thus, women's labor market integration does not seem to be a prerequisite for family enlargement in Germany. However, there is some indication that the perception of economic uncertainty matters for the progression to a second child. Second birth rates declined by 16 percent among the women who are worried about their economic situation compared to women who were not worried. For third births, the pattern is similar, but statistically insignificant. 
Table 2: Results from the Cox model, relative risks of a second and a third birth, (baseline hazard: time since last birth)

\begin{tabular}{|c|c|c|c|c|}
\hline & \multicolumn{2}{|c|}{ Second births } & \multicolumn{2}{|c|}{ Third births } \\
\hline \multicolumn{5}{|l|}{ Calendar period } \\
\hline 1990-2000 & \multicolumn{2}{|l|}{1.01} & \multicolumn{2}{|l|}{0.90} \\
\hline 2001-2006 & \multicolumn{2}{|l|}{1} & \multicolumn{2}{|l|}{1} \\
\hline $2007-2013$ & \multicolumn{2}{|l|}{0.90} & \multicolumn{2}{|l|}{1.03} \\
\hline \multicolumn{5}{|l|}{ Region } \\
\hline East Germany & 0.69 & $* * *$ & 0.77 & $* *$ \\
\hline West Germany & \multicolumn{2}{|c|}{1} & \multicolumn{2}{|l|}{1} \\
\hline \multicolumn{5}{|l|}{ Migrant } \\
\hline Migrant & \multicolumn{2}{|c|}{1} & \multicolumn{2}{|c|}{1} \\
\hline Native & \multicolumn{2}{|c|}{0.87} & \multicolumn{2}{|l|}{0.91} \\
\hline \multicolumn{5}{|l|}{ Education } \\
\hline Low & \multicolumn{2}{|c|}{1} & \multicolumn{2}{|c|}{1} \\
\hline Medium & 1.19 & $* * *$ & \multicolumn{2}{|l|}{0.88} \\
\hline High & 1.83 & $* * *$ & 1.61 & *** \\
\hline \multicolumn{5}{|l|}{ Employment status } \\
\hline In education & 1.53 & $* * *$ & 1.47 & \\
\hline Employed full-time & \multicolumn{2}{|l|}{1} & \multicolumn{2}{|c|}{1} \\
\hline Employed part-time & 1.52 & $* * *$ & 1.52 & $* * *$ \\
\hline Registered unemployed & 1.27 & $*$ & 2.20 & $* * *$ \\
\hline Not working & 1.41 & $* * *$ & 3.06 & $* * *$ \\
\hline \multicolumn{5}{|l|}{ Partner } \\
\hline No partner in household & 0.48 & $* * *$ & 0.64 & $* * *$ \\
\hline Partner in household & \multicolumn{2}{|l|}{1} & \multicolumn{2}{|c|}{1} \\
\hline \multicolumn{5}{|l|}{ Age at first birth } \\
\hline Age 15-20 & \multicolumn{2}{|l|}{1.20} & \multicolumn{2}{|l|}{1.79} \\
\hline Age 21-25 & 1 & & 1 & \\
\hline Age $25-30$ & 0.83 & $* * *$ & 0.54 & $* * *$ \\
\hline Age $30-47$ & 0.54 & $* * *$ & 0.25 & $* * *$ \\
\hline Economic worries & & & & \\
\hline No worries & 1 & & 1 & \\
\hline Some worries & 0.93 & & 0.84 & \\
\hline Big worries & 0.84 & $* *$ & 0.89 & \\
\hline
\end{tabular}

Note: Flag for missing information included; ${ }^{* * *} \mathrm{p}<0.01$; ${ }^{* *} \mathrm{p}<0.05 ;{ }^{*} \mathrm{p}<0.10$.

Source: SOEP 1990-2013 


\subsection{Partner's characteristics}

In a final step, we explore the question of whether the partner's perceptions of economic uncertainty influenced the couple's birth decisions. Furthermore, we examine the interaction effects between the woman's and her partner's perceptions of their economic situation. For this part of the investigation, we have to restrict the analysis to episodes in which the female respondent lived with a (male) partner in the same household. Thus, we are unable to investigate the characteristics of the women who lived in more loose relationships, such as living-aparttogether relationships. In addition, women who had children outside of any union are disregarded here. These population subgroups may be particularly likely to have feelings of economic uncertainty. However, due to the design of the GSOEP, which only surveys the characteristics of the co-residential partner, we are unable to include this sub-population in our investigation.

Table 3 reports the results for the effects of the partner's perception of the couple's economic situation on their birth risks (for the complete results, see Table A2 in the Appendix). As can be seen in the table, the effects of economic uncertainty on the first birth risk were similar for the male and the female respondents: while economic uncertainty did not seem to matter at younger ages, it led older couples to postpone their childbearing plans. For the second and the third birth rates, we also find that economic worries lowered birth intensities. However, here the pattern is more irregular and only statistically significant for third births.

Table 4 reports the finding from the interaction of the female and the male partners' economic worries. The models confirm our assumption that the birth rates would be lower if both partners were worried about their economic well-being. Again, this pattern was most pronounced for first births at higher ages. Here we find that birth rates drop by 36 percent if the partners said they felt economically secure (compared to a couple in which both partners said they were not worried about their economic well-being). For higher order births, the coefficients run in the expected direction, but are insignificant for second and weakly significant for third births. 
Table 3: Results from the Cox model, transition to a first birth (baseline hazard: age of woman), episodes in co-residential partnership, controlled for the partner's perception of the economic situation

\begin{tabular}{|c|c|c|c|c|}
\hline & \multicolumn{2}{|c|}{ First birth } & \multirow[t]{2}{*}{ Second birth } & Third birth \\
\hline & Age 17-26 & Age 27-47 & & \\
\hline Partner's economic worries & & & & \\
\hline No worries & 1 & 1 & 1 & 1 \\
\hline Some worries & 1.05 & 0.97 & 1.05 & $0.77 * *$ \\
\hline Big worries & 1.08 & $0.81 *$ & 0.94 & 0.81 \\
\hline
\end{tabular}

Further variables in model: Age (baseline hazard in first birth model), duration since last birth (baseline hazard in second and third birth model), calendar period, region, migrant status, education, employment status, age at first birth (in second and third birth model), flag for missing information

Note: $* * * \mathrm{p}<0.01 ; * * \mathrm{p}<0.05 ; * \mathrm{p}<0.10$

Source: GSOEP 1990-2013

Table 4: Results from the Cox model, transition to a first birth (baseline hazard: age of woman), episodes in co-residential partnership, controlled for the couple's perceptions of their economic situation

\begin{tabular}{|l|c|c|c|c|}
\hline \multirow{2}{*}{} & \multicolumn{2}{|c|}{ First birth } & \multirow{2}{*}{ Second birth } & \multirow{2}{*}{ Third birth } \\
& Age 17-26 & Age 27-47 & & \\
\hline Partner's economic worries & & & & \\
Both no worries & 1 & 1 & 1 & 1 \\
Both some worries & 1.14 & 0.92 & 0.97 & $0.71 * *$ \\
Both big worries & 1.11 & $0.64 * *$ & 0.84 & $0.74 *$ \\
Only woman big worries & 0.99 & $0.62 * * *$ & 0.85 & 0.79 \\
Only partner big worries & 0.83 & 0.81 & 0.91 & 0.77 \\
Other & 0.82 & 0.91 & 0.93 & 0.77 \\
\hline
\end{tabular}

Further variables in model: Age (baseline hazard in first birth model), duration since last birth (baseline hazard in second and third birth model), calendar period, region, migrant status, education, employment status, age at first birth (in second and third birth model), flag for missing information

Note: *** $\mathrm{p}<0.01 ; * * \mathrm{p}<0.05 ;{ }^{*} \mathrm{p}<0.10$.

Source: GSOEP 1990-2013 


\section{Conclusion}

In this paper, we provided recent empirical evidence on the relationship between the subjective feeling of economic uncertainty and the transitions to the first, the second, and the third child. The analysis was based on rich panel data for Germany for the period 1990-2013. In the investigations, we employed event history techniques in which the subjective feeling of economic uncertainty - i.e., whether the female respondent or her partner was worried about his or her personal economic situation-was inserted into the models as a time-varying covariate.

Previous micro-level studies provided only mixed evidence for the association between measures of economic uncertainty and birth dynamics. We argued that inconsistencies in the findings of these studies might have stemmed from an inability to explore group-specific differences in behavior. Furthermore, we argued that these studies mostly covered the years prior to the financial crisis, when factors other than economic uncertainty, and particularly ideational changes, might have played a greater role in overall birth dynamics. Economic uncertainty may not have emerged as an important determinant of fertility until the new millennium. During the "Great Recession," a large share of the population were affected by economic uncertainty, whereas previously only certain segments of the population were prone to unemployment and other forms of economic uncertainty.

Our data for the period 1990 to 2013 provided mixed evidence. We did not find that the association between economic uncertainty and birth dynamics had changed significantly since the 1990s. We also did not find any clear association between the subjective feeling of economic uncertainty and fertility postponement. However, our analysis which took into account groupspecific differences in behavior provided a more nuanced view. First, we found strong differences in the uncertainty and fertility nexus by people's ages. At younger ages (17-26), economic uncertainty accelerated first birth transitions. However, for the large majority of women and men who had their first child after age 26, economic uncertainty had a very powerful and negative impact on family formation. We also found that progression to a second birth and third child was negatively affected if the woman and her partner were both concerned about their personal economic situation. For higher births, the results were, however, only weakly statistically.

In sum, our results suggest that there are segments of the population for whom a secure economic situation is not a prerequisite for forming a family. If this group is not excluded, it is difficult to find clear-cut associations between economic uncertainty and birth decisions in micro-level studies. The conviction that couples need a secure and stable economic situation before having children is apparently not shared by all population subgroups. This belief is most prevalent among educated women and those who start their family at later ages.

Our study has many limitations, of course. Most importantly, Germany was a country that was not strongly affected by the global financial crisis. Our result may thus not be transferable to other countries who were exposed to more radical economic uncertainties. Furthermore, like many of the other researchers who examined this topic while relying on survey data, we 
grappled with small sample sizes. This was particularly the case for higher order births, for which we were unable to conduct group-specific analyses. We used the subjective feeling of economic uncertainty to operationalize economic uncertainty. Compared to unemployment, this measure seems to be better suited to capturing economic uncertainty, particularly because it affects a less selective part of the population. Nevertheless, we did not control for unobserved population heterogeneity in our models. Thus, we cannot rule out the possibility that some of our "nil-findings" are attributable to the fact that the study population who expressed the greatest economic worries differed systematically from the rest of the population in important dimensions that we were unable to account for.

\section{Acknowledgments}

For his many valuable comments and criticisms, I would like to thank Gunnar Andersson (Stockholm University). I am indebted to Miriam Hils for language editing. Any remaining errors are, of course, my own. 


\section{References}

Adsera, Alicia. 2011. Where are the babies? Labor market conditions and fertility in Europe. European Journal of Population 27: 1-32.

Billingsley, Sunnee. 2011. Economic crisis and recovery: Changes in second birth rates within occupational classes and educational groups. Demographic Research 24: 375-406.

Borg, Mary O'malley. 1989. The income-fertility relationship: Effect of the net price of a child. Demography 26: 301-310.

Brentano, Lujo. 1910. The doctrine of Malthus and the increase of population during the last decades. The Economic Journal 20: 371-393.

Caldwell, John C., und Thomas Schindlmayr. 2003. Explanations of the fertility crisis in modern societies: A search for commonalities. Population Studies 57: 241-263.

De La Rica, Sara, und Amaia Iza. 2005. Career planning in Spain: Do fixed-term contracts delay marriage and parenthood? Review of Economics of the Household 3: 49-73.

Del Bono, Emilia, Andrea Weber und Rudolf Winter-Ebmer. 2014. Fertility and economic instability: the role of unemployment and job displacement. Journal Population Economics (forthcoming).

Ellingsæter, Anne Lise, und Eirin Pedersen. 2015. Institutional trust: Family policy and fertility in Norway. Social Politics (forthcoming).

Esping-Andersen, Gosta, 1999. Social Foundations of Postindustrial Economies. Oxford: Oxford University Press.

Friedlander, Dov, 1992. The British depression and nuptiality: 1873-1896. Journal of Interdisciplinary History 23: 19-37.

Friedman, Debra , Michael Hechter, and Satoshi Kanazawa. 1994. A theory of the value of children. Demography 31: 375-401.

Gebel, Michael, und Johannes Giesecke. 2009. Ökonomische Unsicherheit und Fertilität. DieWirkung von Beschäftigungsunsicherheit und Arbeitslosigkeit auf die Familiengründung in Ost- und Westdeutschland. Zeitschrift für Soziologie 38: 399-417.

Goldstein, Joshua, Michaela Kreyenfeld, Aiva Jasilioniene und Deniz Dilan Karaman Örsal. 2013. Fertility reactions to the "Great Recession” in Europe: Recent evidence from orderspecific data. Demographic Research 29: 85-104.

Gutiérrez-Domènech, Maria. 2008. The impact of the labour market on the timing of marriage and births in Spain. Journal of Population Economics 21: 83-110.

Huttunen, Kristiina, und Jenni Kellokumpu. 2015. The effect of job displacement on couples' fertility decisions. Journal of Labor Economic (forthcoming).

Kravdal, Øystein. 2002. The impact of individual and aggregate unemployment on fertility in Norway. Demographic Research 6: 263-293. 
Kreyenfeld, Michaela. 2002. Time squeeze, partner effect or self-selection? An investigation into the positive effect of women's education on second birth risks in West Germany. Demographic Research 7: 15-48.

Kreyenfeld, Michaela. 2010. Uncertainties in female employment careers and the postponement of parenthood in Germany. European Sociological Review 26: 351-366.

Kreyenfeld, Michaela, und Gunnar Andersson. 2014. Socio-economic differences in the unemployment and fertility nexus in cross-national comparison. Advances in Life Course Research 21: 59-73.

Kreyenfeld, Michaela, Gunnar Andersson und Ariane Pailhé. 2012. Economic Uncertainty and Family Dynamics. Special Collection 12 of Demographic Research.

Lanzieri, Giampaolo. 2013. Towards a ‘baby recession' in Europe? Differential fertility trends during the economic crisis. Eurostat, Statistics in Focus 13.

Lesthaeghe, Ron. 2010. The unfolding story of the second demographic transition. Population and Development Review 36: 211-251.

Luci, Angela, und Olivier Thévenon. 2009. Does economic development drive the fertility rebound in OECD countries? Population (English Selection) 64: 235-272.

Mackenroth, Gerhard. 1953. Bevölkerungslehre. Theorie, Soziologie und Statistik der Bevölkerung. Berlin, Göttingen: Springer.

Matysiak, Anna, und Daniele Vignoli. 2008. Fertility and women's employment: A metaanalysis. European Journal of Population 24: 363-384.

Matz, Klaus-Jürgen. 1980. Pauperismus und Bevölkerung: Die gesetzlichen Ehebeschränkungen in den süddeutschen Staaten während des 19. Jahrhunderts. Stuttgart: Klett-Cotta.

Maul, Katharina. 2012. Der Einfluss der beruflichen Tätigkeit auf die Familiengründung Würzburg: Ergon.

McDonald, Peter. 2000. Gender equity, social institutions and the future of fertility. Journal of Population Research 17: 1-16.

Mills, Melinda, und Hans-Peter Blossfeld. 2003. Globalization, uncertainty and changes in early life courses. Zeitschrift für Erziehungswissenschaft 6: 188-218.

Mombert, Paul. 1907. Die Bevölkerungsbewegung in Deutschland in den letzten Jahrzehnten mit besonderer Berücksichtigun der ehelichen Fruchtbarkeit. Karlsruhe: G. Braunsche Hofdruckerei und Verlag.

Neels, Karel, Zita Theunynck und Jonas Wood. 2013. Economic recession and first births in Europe: Recession-induced postponement and recuperation of fertility in 14 European countries between 1970 and 2005. International Journal of Public Health 58: 43-55.

Neyer, Gerda. 2003. Family policies and low fertility in Western Europe. Journal of Population and Social Security (Supplement to Volume 1): 46-93.

Neyer, Gerda, und Gunnar Andersson. 2008. Consequences of family policies on childbearing behavior: Effects or artifacts? Population and Development Review 34: 699-724. 
Özcan, Berkay, Karl Ulrich Mayer und Joerg Luedicke. 2010. The impact of unemployment on the transition to parenthood. Demographic Research 23: 807-846.

Pailhé, Ariane, und Anne Solaz. 2012. The influence of employment uncertainty on childbearing in France: A tempo or quantum effect? Demographic Research 26: 1-40.

Promberger, Markus Et Al., 2014. Patterns of resilience during socioeconomic crises among households in Europe. IAB-Forschungsbericht, 05/2014.

Rendall, M., O. Ekert-Jaffe, H. Joshi, K. Lynch und R. Mougin. 2009. Universal versus economically polarized change in age at first birth: A French-British comparison. Population and Development Review 35: 89-116.

Richardson, Dominic. 2010. Child and family policies in a time of economic crisis. Children \& Society 24: 495-508.

Rindfuss, Ronald R., Philip S. Morgan und Gray Swicegood. 1988. First Births in America: Changes in the Timing of Parenthood. London: University of California Press.

Schmitt, Christian. 2012a: A cross-national perspective on unemployment and first births. European Journal of Population 28: 303-335.

Schmitt, Christian. 2012b: Labour market integration, occupational uncertainties, and fertility choices in Germany and the UK. Demographic Research 26: 253-292.

Schröder, Jette. 2010: Der Zusammenhang zwischen der Erwerbstätigkeit von Frauen und Ihrer Fertilität. Würzburg: Ergon.

Schultz, Paul T. 1976. Determinants of fertility: A micro-economic model of choice. In Economic Factors in Population Growth. Eds. Ansley Coale, 89-135. New York: Halsted Press.

Sobotka, Tomás, Vegard Skirbekk und Dimiter Philipov. 2011. Economic recession and fertility in the developed world. Population and Development Review 37: 267-306.

Statistics Denmark. 2014. Total fertility rate (www.statbank.dk/FERT1).

Testa, Maria Rita, und Stuart Basten. 2014. Certainty of meeting fertility intentions declines in Europe during the ‘Great Recession’. Demographic Research 31: 687-734.

Van De Kaa, Dirk J. 1987. Europe’s Second Demographic Transition. Population Bulletin 42: 3-57.

Vignoli, Daniele, Sven Drefahl und Gustavo De Santis. 2012. Whose job instability affects the likelihood of becoming a parent in Italy? A tale of two partners. Demographic Research 26: 4162.

Vlachadis, Nikolaos, Zoe Iliodromiti, Maria Vlachadi und George Creatsas. 2014. Greece’s birth rates and the economic crisis. Lancet 383: 692-693.

Wagner, Gert G., Joachim R. Frick und Jürgen Schupp. 2007. The German Socio-Economic Panel Study (SOEP): Scope, evolution and enhancements. Schmollers Jahrbuch 127: 139-169.

Willis, Robert J. 1987. What have we learned from the economics of the family? The American Economic Review 77: 68-81. 
Table A1: Occurrences (Occ) and time of exposures (Exp), all episodes

\begin{tabular}{|c|c|c|c|c|c|c|c|c|}
\hline & \multicolumn{4}{|c|}{ First birth } & \multicolumn{2}{|c|}{ Second birth } & \multicolumn{2}{|c|}{ Third birth } \\
\hline & \multicolumn{2}{|c|}{ Age 17-26 } & \multicolumn{2}{|c|}{ Age 27-47 } & & & \multirow[b]{2}{*}{ Exp } & \multirow[b]{2}{*}{ Occ } \\
\hline & Exp & Occ & Exp & Occ & Exp & Occ & & \\
\hline \multicolumn{9}{|l|}{ Calendar period } \\
\hline $1990-2000$ & $39 \%$ & 432 & $31 \%$ & 362 & $39 \%$ & 688 & $39 \%$ & 244 \\
\hline 2001-2006 & $37 \%$ & 285 & $37 \%$ & 400 & $36 \%$ & 521 & $37 \%$ & 196 \\
\hline 2007-2013 & $24 \%$ & 110 & $33 \%$ & 253 & $25 \%$ & 298 & $24 \%$ & 113 \\
\hline \multicolumn{9}{|l|}{ Region } \\
\hline East Germany & $74 \%$ & 583 & $85 \%$ & 842 & $70 \%$ & 1224 & $71 \%$ & 452 \\
\hline West Germany & $26 \%$ & 244 & $15 \%$ & 173 & $30 \%$ & 283 & $29 \%$ & 101 \\
\hline \multicolumn{9}{|l|}{ Migrant/ foreigner } \\
\hline Migrant & $92 \%$ & 689 & $91 \%$ & 912 & $87 \%$ & 1217 & $84 \%$ & 406 \\
\hline Native & $8 \%$ & 138 & $9 \%$ & 103 & $13 \%$ & 290 & $16 \%$ & 147 \\
\hline \multicolumn{9}{|l|}{ Education } \\
\hline Low & $66 \%$ & 356 & $14 \%$ & 108 & $17 \%$ & 315 & $17 \%$ & 161 \\
\hline Medium & $28 \%$ & 425 & $60 \%$ & 613 & $71 \%$ & 940 & $70 \%$ & 312 \\
\hline High & $3 \%$ & 25 & $23 \%$ & 271 & $9 \%$ & 209 & $9 \%$ & 62 \\
\hline Missing & $3 \%$ & 21 & $3 \%$ & 23 & $3 \%$ & 43 & $4 \%$ & 18 \\
\hline \multicolumn{9}{|l|}{ Employment status } \\
\hline In education & $55 \%$ & 189 & $4 \%$ & 31 & $2 \%$ & 46 & $1 \%$ & 10 \\
\hline Employed & $27 \%$ & 414 & $70 \%$ & 798 & $33 \%$ & 199 & $30 \%$ & 58 \\
\hline Part-time & $4 \%$ & 64 & $12 \%$ & 85 & $30 \%$ & 440 & $33 \%$ & 134 \\
\hline Registered unemployed & $5 \%$ & 83 & $6 \%$ & 47 & $10 \%$ & 124 & $9 \%$ & 59 \\
\hline Not working & $7 \%$ & 68 & $7 \%$ & 45 & $21 \%$ & 587 & $24 \%$ & 267 \\
\hline Missing & $1 \%$ & 9 & $1 \%$ & 9 & $3 \%$ & 111 & $3 \%$ & 25 \\
\hline \multicolumn{9}{|l|}{ Economic worries } \\
\hline Big worries & $22 \%$ & 241 & $21 \%$ & 159 & $26 \%$ & 344 & $25 \%$ & 150 \\
\hline Some worries & $52 \%$ & 445 & $53 \%$ & 543 & $55 \%$ & 838 & $56 \%$ & 287 \\
\hline No worries & $22 \%$ & 134 & $26 \%$ & 310 & $18 \%$ & 321 & $19 \%$ & 113 \\
\hline Missing & $4 \%$ & 7 & $1 \%$ & 3 & $0 \%$ & 4 & $0 \%$ & 3 \\
\hline \multicolumn{9}{|l|}{ Age at first birth } \\
\hline Age 15-20 & & & & & $8 \%$ & 90 & $10 \%$ & 86 \\
\hline Age 21-25 & & & & & $36 \%$ & 480 & $41 \%$ & 245 \\
\hline Age 25-30 & & & & & $33 \%$ & 569 & $31 \%$ & 159 \\
\hline Age 30-47 & & & & & $23 \%$ & 368 & $18 \%$ & 63 \\
\hline \multicolumn{9}{|l|}{ Partner } \\
\hline No partner in household & $80 \%$ & 313 & $39 \%$ & 170 & $18 \%$ & 108 & $13 \%$ & 47 \\
\hline Partner in household & $20 \%$ & 514 & $61 \%$ & 845 & $82 \%$ & 1399 & $87 \%$ & 506 \\
\hline & & & & 1,01 & & 1,50 & & \\
\hline Total & $100 \%$ & 827 & $100 \%$ & 5 & $100 \%$ & 7 & $100 \%$ & 553 \\
\hline
\end{tabular}


Table A1 (continued): Occurrences (Occ) and time of exposures (Exp), co-residential episodes

\begin{tabular}{|l|rr|rr|rr|rr|}
\hline & \multicolumn{7}{|c|}{ First birth } & \multicolumn{2}{c|}{ Second birth } & \multicolumn{2}{c|}{ Third birth } \\
& \multicolumn{2}{|c|}{ Age 17-26 } & \multicolumn{2}{c|}{ Age 27-47 } & & & \\
& Exp & Occ & Exp & Occ & Exp & Occ & Exp & Occ \\
\hline Partner's economic worries & & & & & & & & \\
Big worries & $25 \%$ & 139 & $19 \%$ & 109 & $23 \%$ & 296 & $22 \%$ & 124 \\
Some worries & $55 \%$ & 284 & $54 \%$ & 460 & $57 \%$ & 791 & $57 \%$ & 270 \\
No worries & $20 \%$ & 88 & $27 \%$ & 273 & $20 \%$ & 308 & $20 \%$ & 109 \\
Missing & $0 \%$ & 3 & $0 \%$ & 3 & $0 \%$ & 4 & $0 \%$ & 3 \\
\hline economic worries & & & & & & & & \\
Both big worries & $10 \%$ & 66 & $8 \%$ & 43 & $13 \%$ & 158 & $12 \%$ & 69 \\
Both some worries & $28 \%$ & 171 & $30 \%$ & 265 & $35 \%$ & 503 & $37 \%$ & 166 \\
Both no worries & $8 \%$ & 44 & $14 \%$ & 131 & $11 \%$ & 164 & $11 \%$ & 68 \\
Only woman big worries & $15 \%$ & 73 & $11 \%$ & 66 & $10 \%$ & 138 & $10 \%$ & 55 \\
Only partner big worries & $9 \%$ & 41 & $8 \%$ & 60 & $10 \%$ & 132 & $10 \%$ & 51 \\
Other & $30 \%$ & 119 & $29 \%$ & 280 & $22 \%$ & 304 & $21 \%$ & 97 \\
\hline Total & $100 \%$ & 514 & $100 \%$ & 845 & $100 \%$ & 1399 & $100 \%$ & 506 \\
\hline
\end{tabular}


Table A2: Results from Cox-model, relative risks, transition to first birth (baseline hazard: age of woman), second and third birth (baseline hazard: duration since last birth), episodes in coresidential partnership

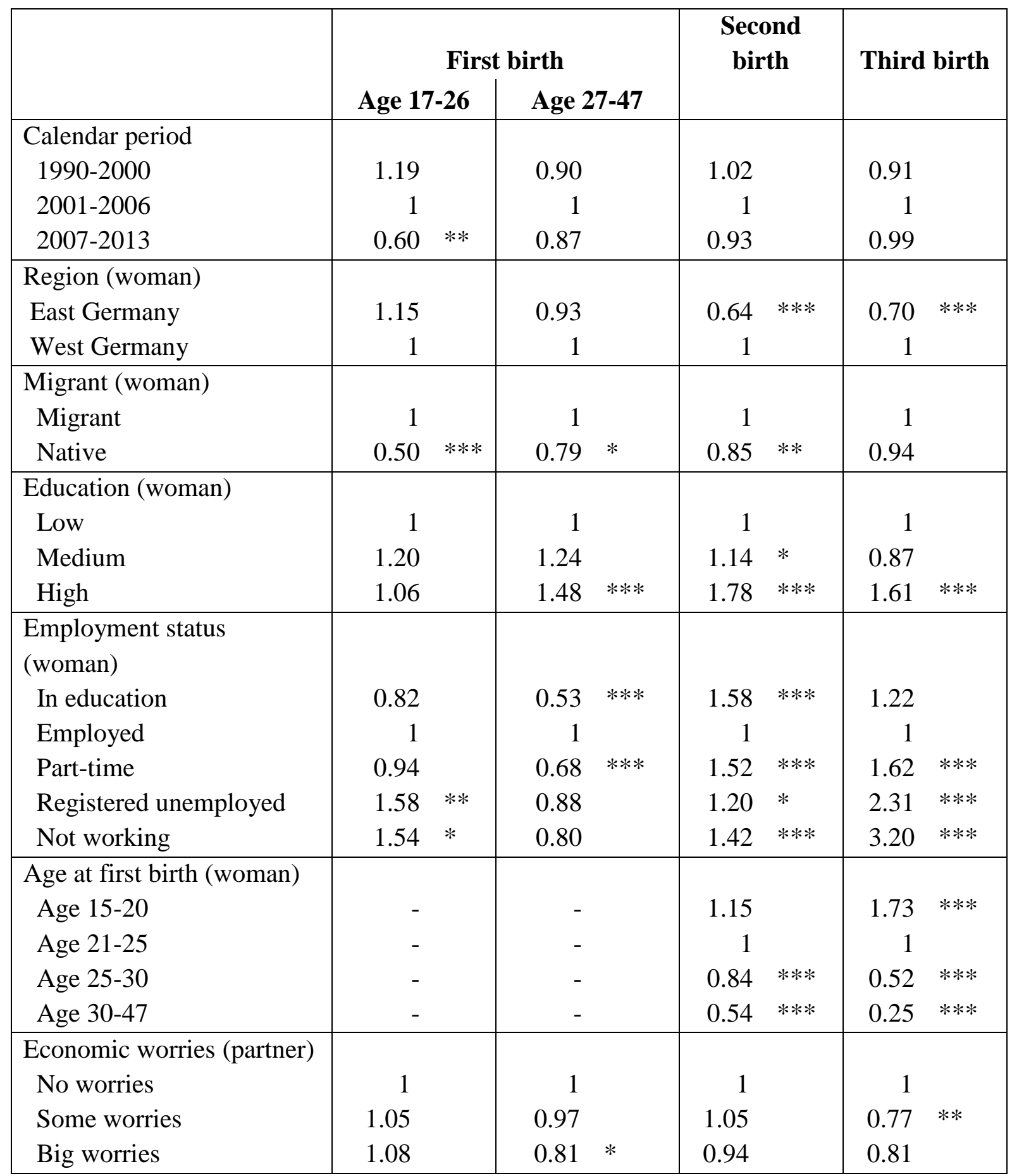

Note: Flag for missing information included; ${ }^{* * *} \mathrm{p}<0.01 ;{ }^{* *} \mathrm{p}<0.05 ;{ }^{*} \mathrm{p}<0.10$.

Source: GSOEP 1990-2013 